AT-TAJDID: Jurnal Pendidikan Dan Pemikiran Islam

(p-ISSN: 2548-5784 |e-ISSN: 2549-2101)

Vol. (5)(01), (Januari-Juni) (2021), (15-27)

Doi: http://dx.doi.org/10.24127/att.v5i01.1471

\title{
RITUAL KEAGAMAAN SEBELUM BELAJAR SELAMA PEMBELAJARAN JARAK JAUH (STUDI KASUS DI SEKOLAH SWASTA ISLAM DAN SEKOLAH NEGERI)
}

\author{
Anita Aisah $^{1}$ \\ Fakultas Agama Islam, Universitas Muhammadiyah Yogyakarta ${ }^{1}$ \\ anita.aisah@umy.ac.id ${ }^{1}$ \\ Ratna Sari ${ }^{2}$ \\ Fakultas Agama Islam, Universitas Muhammadiyah Yogyakarta² \\ ratna.sari@.umy.ac.id ${ }^{2}$
}

\begin{abstract}
ABSTRAK
Situasi pandemi membuat sekolah harus melakukan beberapa penyesuaian kegiatan termasuk ritual keagamaan sebelum belajar. Penelitian ini memiliki tujuan untuk menggali bagaimana ritual keagamaan sebelum belajar selama masa pandemi covid-19. Jenis penelitian ini merupakan penelitian studi kasus dengan pendekatan kualitatif. Metode pengambilan data dilakukan melalui wawancara dan observasi. Waktu pengambilan data dilakukan pada tanggal 7 - 14 November 2020. Subjek pada penelitian ini adalah pendidik dan orangtua di empat sekolah. Empat sekolah terdiri dari dua sekolah Negeri dan dua sekolah swasta. Hasil yang diperoleh adalah kegiatan ritual keagamaan di empat sekolah berbeda-beda. Hal ini karena jenis sekolah, Negeri dan Swasta yang berbasis agama. Selain itu ada dua sekolah yang sudah melakukan pembelajaran tatap muka. Orangtua merupakan faktor pendukung dalam pelaksanaan ritual keagaman sebelum belajar selama pembelajaran jarak jauh.
\end{abstract}

Kata Kunci: Ritual Keagamaan; Sebelum Belajar; Pandemi

\begin{abstract}
The pandemic situation has forced schools to make several adjustments to activities including religious rituals before studying. This study aims to explore how religious rituals before learning during the Covid-19 pandemic. This type of research is a case study research with a qualitative approach. The data collection method is done through interviews and observations. When data collection was carried out on November 7-14, 2020. The subjects in this study were educators and parents in four schools. The four schools consist of two public schools and two private schools. The results obtained were different religious ritual activities in four schools. This is due to the type of school, State and private which are religion based. In addition, there are two schools that have conducted face-to-face learning. Parents are a supporting factor in the implementation of religious rituals before learning during distance learning.
\end{abstract}

Keywords: Religious Rituals; Before Studying; Pandemic 


\section{A. PENDAHULUAN}

Tujuan pendidikan di Indonesia adalah membentuk manusia yang berkarakter. Pidato Menteri Pendidikan Indonesia Nadiem Makariem juga menjelaskan bahwa pendidikan karakter merupakan salah satu dari dua penguatan dalam membangun sumber daya manusia. Pada tahun 2010, Kemendiknas telah merumuskan ada 18 karakter yang dibentuk melalui pendidikan (Kusumawardhani, 2013). Salah satu karakter yang dibentuk adalah karakter religiusitas.

$$
\text { Religiusitas adalah tingkat }
$$

ketertarikan individu terhadap agamanya. Individu yang menghayati ajaran agamanya akan berpengaruh pada pola pikir dan perilakunya (Gufron \& Risnawati, 2010; Fathoni, et al., 2021) Religiusitas menjadi salah satu karakter yang dibentuk di dalam sistem pendidikan karena individu yang memiliki religiusitas baik, maka individu akan menginternalisasi dan menghayati ajaran agamanya dalam setiap perilaku belajarnya (Syaikhoni, et al., 2021; Bahri, et al., 2021). Karakter religius dikembangkan sejak anak berusia sedini mungkin. Pengalaman keagamaan selama anak-anak dan remaja akan berdampak pada religiusitasnya pada masa dewasa. Masa kanak-kanak dan remaja sering menjadi subjek pemaparan agama baik di dalam maupun di luar rumah. Pengembangan kepercayaan agama sebagian disebabkan oleh pengaruh lingkungan, seperti interaksi dengan keluarga, guru dan teman sebaya (Tratner, et al., 2017; Cahyono, et al., 2017; Yolanda \& Kailola, 2021). Salah satu faktor eksternal yang mempengaruhi religiusitas adalah interaksi siswa dengan lingkungan sekolah. Sekolah memiliki kegiatan kegamaan sebagai upaya peningkatan religiusitas siswa (Amri, et al., 2020). Studi pendahuluan dilakukan di Sekolah Muhammadiyah di Yogyakarta. Ada kegiatan sholat dhuha rutin yang dilakukan setiap pagi. Beberapa sekolah menjadwalnya sholat dhuhanya bergantian karena tempat yang tidak cukup untuk semua siswa. Berdoa juga menjadi ritual rutin yang dilakukan di dalam kelas sebelum pelajaran dimulai.

Ritual keagamaan juga dilakukan di Universitas Muhammadiyah (UMY). Ada kewajiban yang harus dilakukan sebelum kuliah dimulai yaitu tadarus AlQuran. UMY juga memiliki buku panduan tadarus sebagai pedoman dosen melakukan aktivitas tadarus di kelas. Di Jombang, ada sekolah yang memiliki kebiasaan membaca asmaul husna sebelum pembelajaran. Sekolah tersebut adalah Sekolah Dasar Negeri Latsari (Siswoyo, 2018). Kebiasaan membaca asmaul husna sebelum pembelajaran dimulai sejak awal tahun 2018. Di beberapa sekolah islam di Kalimantan Selatan juga memiliki kebiasaan membaca Asmaul Husna. Menurut Hasbi (Kanwil Kemenag Kalsel, 2017), tujuan membaca asmaul husna sebelum belajar adalah agar siswa mendapatkan manfaat, berkah dan senantiasa mendapatkan kebaikan dan perlindungan dari Allah SWT.

Bagi individu yang beragama islam memang diajarkan untuk mengingat Allah sebelum belajar. Hal ini tertera pada surat yang pertama turun yaitu surat Al Alaq. Manusia diberikan tugas untuk belajar dengan membaca. Membaca harus didahului dengan berdoa atau menyebut nama Allah. Berdasarkan wawancara pada ahli tafsir AlQuran, bahwa semua ilmu yang ada di dunia adalah milik Allah SWT. Kita manusia belajar karena mencari ilmunya Allah sehingga sangat dianjurkan untuk memulai semua kegiatan belajar dengan menyebut Allah (Rachmadhani, 2019);Palupi, Syahid, 2020).

Berdasarkan studi pendahuluan melalui wawancara pada beberapa orangtua yang menerapkan kebiasaan belajar di rumah. Apabila belajar didahului dengan membaca AlQuran, konsentrasi anaknya menjadi lebih baik daripada saat tidak ada aktivitas membaca Al-Quran sebelum belajar. Hasil pilot study yang dilakukan oleh peneliti didukung oleh 
penelitian yang dilakukan oleh Julianto \& Estem (2011). Hasil penelitiannya menunjukkan bahwa terjadi kenaikan kemampuan memori yang signifikan pada kelompok eksperimen setelah diberikan perlakukan berupa membaca AlQuran.

Pada awal tahun 2020, dunia digoncangkan dengan pandemi covid-19. Sektor pendidikan adalah salah satu sektor yang terdampak pandemi-19. Situasi pandemi covid memaksa kita agar mampu beradaptasi dengan kebiasaan baru dalam melaksanakan kegiatan pendidikan. Salah satu kebiasaan baru dalam sistem pendidikan selama masa pandemi adalah proses pembelajaran jarak jauh (PJJ) (Ilyasa, et al., 2020; Rahimah, et al., 2020). Akibatnya permasalahan pembelajaran yang biasa dilaksakanan secara langsung di sekolah, akhirnya beralih ke rumah siswa. Hal tersebut dilakukan sebagai upaya menurunkan angka penyebaran covid-19.

Kebijakan pembelajaran jarak jauh yang ditetapkan oleh pemerintah sejak pertengahan bulan Maret 2020, berdampak pada kegiatan ritual kegamaan sebelum belajar yang dilakukan di rumah. Pada penelitian ini ingin mengetahui bagaimana ritual keagamaan sebelum belajar selama pembelajaaran jarak jauh? Penelitian ini bertujuan untuk mengetahui dan menganalisis bagaimana kebijakan sekolah dan penerapan di lapangan terkait ritual keagamaan sebelum pembelajaran.

\section{B. LANDASAN TEORI}

Penelitian ini merupakan penelitian yang menggunakan variabel ritual keagamaan terhadap aspek psikologis. Pada tinjauan pustaka ini akan dijelaskan Ritual keagamaan yang meliputi: pembacaan Asmaul Husna, membaca AlQuran, Tadarus dan Berdoa. Aspek psikologis yang akan dibahas lebih detail adalah kognitif (Prestasi belajar), afeksi (religiusitas) dan psikomotorik (keaktifan siswa di kelas)

1. Ritual Keagamaan
Ritual adalah serangkaian kegiatan yang dilaksanakan untuk tujuan simbolis. Rritual dilakukan berdasarkan agama juga bisa berdasarkan tradisi. Ritual keagamaan dimodelkan dalam berbagai bentuk simbol (Wahab, 2011). Pada masa terdahulu, ritual diwujudkan dalam bentuk tarian, sesajen dan baca mantra. Pada penelitian ini ritual keagamaan yang dimaksudkan adalah ritual keagamaan sebelum pembelajaran dimulai. Ritual agama yang akan dijabarkan adalah Membaca Quran, tadarus, membaca Asmaul husna dan berdoa.

Membaca Quran adalah salah satu ritual keagamaan yang menjadi tradisi di sekolah sekolah, terutama sekolah islam. Membaca AlQuran telah diteliti oleh akademisi. Nayef dan Wahab (2018) melakukan penelitian dampak membaca Quran terhadap emosi manusia. Pelafalan Al-Quran menghasilkan relaksasi yang signifikan yang mungkin disebabkan oleh karena Al-Quran memiliki efek spesifik pada jantung manusia yang mengakibatkan beberapa hormon dan bahan kimia yang memiliki tugas untuk relaksasi (Nayef \& Wahab, 2018). Relaksasi spiritual dan fisik dapat dicapai dengan membaca Al-Quran. Dalam teknik mendengarkan, membaca, dan melihat teks subjek Al-Quran ini dapat melibatkan seluruh tubuh. Seluruh proses akan dikendalikan oleh otak, sebagai hasilnya selama latihan ini seluruh tubuh akan menerima ketenangan. Kelelahan dan kebosanan akan selesai. Cara biofeedback fisiologis ini menyediakan bahan makanan untuk jiwa.

Membaca Al-Quran juga dapat meningkatakan kecerdasan spiritual siswa. Praktek membaca Al-Quran menjadi tradisi di SMP 2 Kota Blitar. Fitrinsyah (Fitriansyah, 2018) melakukan pengukuran kecerdasan spiritual pada siswa SMP 2 
Kota Blitar yang telah terbiasa membaca AlQuran sebelum pembelajaran di mulai. Hasilnya adalah kecerdasan spiritual siswa SMP 2 Kota Blitar termasuk kategori tinggi. Selain itu adalah hubungan yang positif antara kebiasaan membaca Al Quran dengan kecerdasan spiritual siswa. Membaca AlQuran juga dapat meningkatkan kemampuan mengingat jangka pendek (Fitriansyah, 2018; Iswati, et al., 2021). Penelitian yang dilakukan oleh Julianto \& Estem (2011) menunjukkan bahwa memori jangka pendek. Penelitian tentang manfaat membaca AlQuran juga dilakukan oleh Investigating the EEG signls of the volunteers showed that, when a Persianspeaking Muslim listens to the Quran consciously, meaning that he knows it is from the Holy Quran, the relative power of theta and alpha brain signals will increase. Also, when he is listening to the Quran unconsciously, which means that he does not know it is from the Holy Quran, the relative power of theta brain signal will increase

Ritual keagamaan yang lain yang dilakukan sebelum pembelajaran antara lain berdoa dan membaca asmaul husna. Doa adalah salah satu sarana berkomunikasi antara manusia dengan Allah SWT dalam kondisi tertentu (Mursalim, 2011). Salah satu kondisi tertentu adalah kondisi sebelum pembelajaran dimulai. Secara garis besar berdoa memiliki dua tujuan yaitu sebagai sarana mengakui kebesaran Allah SWT. Kedua, manusia menyandarkan segala kebutuhan kepada Allah.

Ritual keagamaan selanjutnya adalah membaca Asma'ul Husna. Asma'ul Husna merupakan nama atau sifat Allah yang berjumlah 99 nama/sifat (Kusuma, 2011). Membaca Asma'ul Husna memiliki banyak manfaat. Salah satu manfaatnya adalah agar dapat memperoleh kemudahan. Apabila diterapkan sebelum pembelajaran maka tujuan membaca Asmaul Husna adalah agar Allah memberikan kemudahan memproses informasi pembelajaran bagi siswa (Kusuma, 2011).

\section{Religiusitas}

Religiusitas merupakan internalisasi nilai nilai agama dalam diri individu. Internalisasi berkaitan dengan kepercayaan terhadap ajaran agama baik di dalam hati maupun uacapan (Khalek, 2009). Menurut Glock dan Starck dalam Khalek (2009), religisuitas memiliki lima dimensi yaitu dimensi keyakinan, praktik keagamaan, pengalaman religius, pengetahuan agama dan konsistensi.

Menurut Glock dan Starck dalam Khalek (2009), Religiusitas memiliki lima dimensi meliputi: Dimensi keyakinan; dimensi peribadatan atau praktek agama; dimensi pengalaman; dimensi ihsan; dan dimensi pengetahuan. Ritual keagamaan sebelum belajar merupakan bagian dari dimensi peribadatan atau praktek agama. Dimensi peribadatan berkaitan dengan frekuensi, intensitas dan pelaksanaan ibadah seseorang. Praktek ibadah terdiri dari dua jenis yaitu ritual dan ketaatan. Ritual mengacu pada praktek-praktek suci atau tindakan keagaman formal yang semua agama mengharapkan semua penganut melaksanakannya.

Peningkatan religiusitas dipengaruhi oleh beberapa faktor, salah satunya adalah faktor pendidikan dan pengajaran. Nilainilai yang diajarkan oleh sekolah agama akan menguatkan perilaku dan keyakinan beragama seseorang (Diesendruck, 2008).

3. Perkembangan Religiusitas siswa

Subandi (2019) mengatakan bahwa proses perkembangan kehidupan beragama 
cukup uni apabila dibandingkan dengan perkembangan aspek-aspek yang lain pada diri manusia. Pada umumnya perkembangan fisik, kognitif dan sosioemosi mengalami peningkatan pada masa kanak-kanak sampai pada masa remaja atau dewasa, kemudian mengalami penurunan pada saat menuju masa lansia. Penelitian yang dilakukan oleh Hidayat (Subandi, 2019) membuktikan bahwa ada semakin tinggi usia seseroang maka tingkat keberagamannya juga semakin tinggi.

Perkembangan keagamaan pada bab ini dipaparkan dalam tiga tahap yaitu tahap perkembangan anak-anak, remaja dan dewasa. Pada dasarnya dalam diri manusia terdapat religious instinct. Religious instinct merupakan potensi yang secara alamiah membawa manusia dalam kehidupan beragama (Subandi, 2019). Beberapa faktor yang mempengaruhi religious instinct meliputi faktor internal (kognitif dan kepribadian) serta faktor lingkungan terutama keluarga.

Mekanisme psikologis beragama pada masa kanak-kanak yang sangat menonjol adalah mekanisme imitasi. Kemampuan beragama anak berkembang lewat proses peniruan. Pada awalnya, anak meniru perilaku beragama orangtuanya. Menurut Clark (Jalaludin, 2007), imitatif merupakan salah satu ciri beragama pada masa kanak-kanak. Anak-anak akan menirukan apa yang diyakini dan dilakukan oleh orang di sekitarnya.

Pada masa kanak-kanak, keluarga memiliki pengaruh yang dominan bagi perkembangan keberagamaan seseorang. Seorang anak yang dibesarkan dalam keluarga yang religius akan lebih besar keungkinannya berkembang menjadi lebih religius dibandingkan dengan yang tidak religius. Anak yang dilahirkan di dalam keluarga yang beragama Islam, maka religious instinct akan berkembang dalam tradisi islam dan anak akan menjadi seorang muslim (Diesendruck, 2008).

Konsep KeTuhanan anak-anak masuk dalam tahap Fairy-Tales Stage (Tahap Dongeng) untuk anak usia 3-6 tahun dan Realistic Stage (Tahap Realtistik) untuk usia 7 - 12 tahun. Pada tahap mendongeng anak mendeskripsikan Tuhan seperti cerita-cerita dalam dongeng, salah satunya dengan sosok yang bersayap, raksasa ataupun hantu.

Pada tahap realistik, anak mulai mendapatkan pelajaran yang merangsang intelektualitasnya. Namun fase perkembangan kognitifnya masih termasuk perkembangan konkrit. Gambaran Tuhan pada masa ini berdifat konkrit dan antromorphis. Anak usia 7 - 12 tahun mendeskripsikan Tuhan seperti manusia yang memiliki tangan, kaki, mata, memiliki rumah dan sebagainya.

Tahap keberagaman yang kedua adalah keberagamaan pada masa remaja. Kondisi psikologis remaja memiliki pengarih yang cukup besar dalam kehidupan beragama mereka. Perkembangan kognitif remaja masuk pada fase perkembangan kognitif operasional formal. Menurut Piaget (Santrock, 2017), pola berfikir remaja adalah mampu berfikir abstrak, teoritik dan kritis. Sikap kritis remaja juga tampak dalam kehidupan beragama. Remaja tidak menerima bergitu saja ajaran agama yang diajarkan oleh orangtuanya. Remaja mulai mempertanyakan pelajaran agama yang pernah mereka dapatkan pada waktu masih kanak-kanak.

Tahap

perkembangan keberagaamaan yang terakhir adalah pada tahap dewasa. Seseorang yang sudah masuk pada tahap dewasa pada umumnya 
telah mencapai kemantapan dan kematangan baik secara psikologis, sosial maupun ekonomis. Namun tidak semua orang dewasa matang dalam aspek keberagamaannya. Ada dua perilaku yang masih dibawa sejak masa kanak-kanak yaitu perilaku ritualistik dan egosentrik (Desmon, 2010). Perilaku ritualistik ditunjukkan dengan prang dewasa yang melaksanakan ritual ibadah hanya sebagai bentuk kebiasaan yang dibawa sejak masa kanak-kanak. Bentuk egosentrisme terlihat pada doa orang dewasa yang masih terpusat pada kebutuhan dan keinginan diri sendiri, kelompok maupun keluarga.

Seorang dewasa yang perkembangan agamanya menagalami berkembangan dengan baik akan menerima agamanya dengan kritis. Seorang dewasa mampu menempatkan rasio sebagai salah satu bagian dari kehidupan beragamanya selain dari segi emosional, sosial maupun spirital. Selain itu, ada keselarasan antara tingkah laku seseorang dengan nilai moral dan agamanya.

\section{METODE PENELITIAN}

Penelitian ini merupakan penelitian dengan metode studi kasus. Menurut Yin (2014) Studi kasus merupakan sebuah penelitian yang mengekspilasi suatu fenomena dengan menggunakan berbagai sumber data. Yin (2014) memaparkan tentang karakteristik metode studi kasus. Karakteristik khas dari studi kasus adalah menjawab pertanyaan bagaimana dan mengapa pada suatu fenomena yang menjadi fokus penelitian. Menurut Yin (2014), kekuatan dari penelitian studi kasus adalah kedalamannya memahami permasalahan atau fenomena walaupun jumlah individu, kelompok maupun lembaga yang diteliti terbatas.
Pendekatan yang digunakan pada penelitian ini menggunakan pendekatan kualitatif. Pendekatan kualitatif digunakan sesuai dengan topik yang diangkat yaitu ritual keagamaan sebelum belajar pada siswa selama pembelajaran jarak jauh. Penelitian dengan pendekatan kualiatif merupakan penelitian yang bertujuan untuk memahami fenomena tentang apa yang dialami oleh individu meliputi perilaku, persepsi, motivasi dll secara holistik (Moleong, 2014).

Penelitian ini dilakukan di Yogyakarta dengan metode pengambilan data dilakukan secara online. Berdasarkan studi pendahuluan yang dilakukan oleh peneliti, maka penelitian dilakukan di empat sekolah. Empat sekolah memiliki karakteristik ritual keagamaan yang unik sebelum pandemi. Peneliti ingin mengetahui bagaimana penerapan ritual keagamaan tersebut diterapkan ketika masa pandemi.

Pemilihan subjek penelitian dilakukan dengan prosedur sampling purposif dengan karakteristik yaitu orangtua dan guru yang melaksanakan pembelajaran online.

Menurut Sugiyono (2011), Penelitian dengan pendekatan kualitatif merupakan penelitian digunakan untuk mengeksplorasi kondidi alamiah subjek, dimana peneliti adalah instrumen kunci penelitian. Peneliti mengoptimalkan proses penelitian sehingga dapat membangun rapport yang baik dengan subjek penelitian. Hal ini sebagai dasar dari hubungan peneliti dengan subjek penelitian. Harapannya adalah peneliti dapat menggali informasi yang diperlukan sebagai data penelitian dengan mudah. Peneliti berperan sebagai pengarah dan pengambil data, dimana peneliti sangat mengetahui konsep dan kondisi di 
lapangan dalam penelitian ini. Peneliti mencari data dengan wawancara mendalam dan tidak terlibat pada aktivitas yang dilakukan oleh subjek penelitian.

Sumber data pada penelitian ini adalah respon subjek melalui kata-kata. Ada eman sumber data yang dapat digunakan dalam penelitian kualitatif yaitu dokumen, rekamana arsival, wawancara dan observasi secara langsung (Yin, 2014). Sumber data pada penelitian ini dilakukan melalui wawancara. Wawancara dilakukan dengan metode wawancara semi terstruktur dan lebih banyak dilakukan secara online.

Peneliti melakukan analisis data penelitian setelah semua data telah terkumpul. Analisis data penelitian dilakukan melalui beberapa tahap yaitu mengklasifikasi, mengorganisasi, menkombinasi kemudian membuat tabulasi data menjadi unit-unit yang dapat dikelola. Yin (2014) memaparkan bahwa bracketing merupakan salah satu teknik untuk membantu menganalisi data penelitian. Bracketing merupakan teknik penggolongan jawaban subjek berdasarkan proporsi teoritikal pada penelitian studi kasus. Proporsi ini membantu untuk berfokus pada beberapa data penting dan mengabaikan data yang tidak relevan. Tahap terkahir adalah menginterpretasi data dengan cara menganalisis kasus untuk mengembangkan kerangka deskripsi data penelitian.

\section{HASIL DAN PEMBAHASAN}

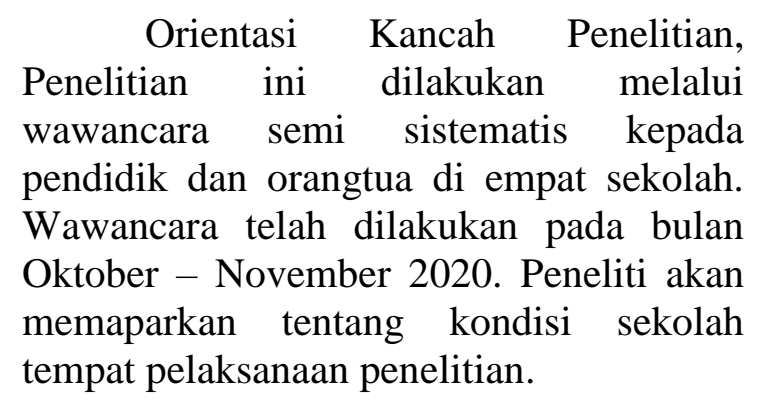

SDN di Semarang (SD A). SDN-A merupakan salah satu SD Negeri terletak di Jalan Sadewa Pendrikan Kidul, Kecamatan Semarang, Kota Semarang Jawa Tengah. SD yang telah memiliki akreditasi A ini memiliki siswa laki-laki sejumlah 172 dan siswa perempuan 191 . Mayoritas agama siswa pada SD A adalah islam.

SDN di Tamanan Bantul Yogyakarta (SD B). SD Negeri yang terletak di desa Tamanan, Kecamatan Banguntapan, Kabupaten Bantul Yogyakarta. SD B yang telah memiliki akreditasi A ini juga memiliki 17 guru, siswa laki-laki sejumlah 175 dan siswa Perempuan sejumlah 162. Fasilitas sekolah ini adalah ruang kelas yang berjumlah 12 kelas, perpustakaan 1 ruang dan ruang sanitasi sebanyak 11 . Proses pembelajaran menggunakan kurikulum K-13.

SD Muhammadiyah di Yogyakarta (SD C). SD swasta sebagai tempat penelitian ini adalah SD Muhammadiyah di Pakel. SD ini terletak di komplek Masjid Mataram, jalan Pakel Baru no. 40, Kelurahan Sorosutan, Kecamatan Umbulharjo, Kota Yogyakarta. SD C merupakan sekolah dengan sistem fullday school sejak tahun 1998. Program khusus sekolah ini adalah Tahfidz. Fasilitas sekolah ini meliputi 18 ruang kelas, ruang laboratorium, perpustakaan dan masjid. Ada lapangan yang bisa dijadikan kegiatan olahraga para siswa. Setiap tahun ajaran baru, SD C mendapat tambahan siswa sekitar 105 siswa.

SD Muhammadiyah di Yogyakarta (SD D). SD swasta selanjutnya adalah SD Muhamamdiyah di Nitikan, Sorosutan, Umbulharjo Yogyakarta. SD-D ini merupakan fillial dari SD Sapen. Namun sekarang sudah mandiri. SD D ini memiliki empat kampus yang berbeda, di Kranon, di kompleks Masjid Al-Ishlaah Nitikan, di Komplek Masjid Muthohirin serta di Giwangan. SD D ini memfasilitasi beberapa siswa untuk mengembangkan bakatnya, seperti senin dan olah raga. Setiap jenjang kelas terdapat empat kelas 
dari kelas A sampai D, setiap kelas terisi 24 siswa.

Hasil Wawancara dan Observasi Wawancara dilakukan bertujua untuk menggali data bagaimana sekolah menerapkan ritual keagamaan selama proses pembelajaran jarak jauh. Wawancara dilakukan dengan metode wawancara semi terstruktur. Wawancara dilakukan oleh peneliti kepada guru dan wali murid kelas 1 di empat sekolah yaitu dua sekolah negeri dan dua sekolah swasta. Hasil wawancara adalah sebagai berikut:

SD-A: Wawancara dilakukan oleh peneliti dengan guru PAI di SD-A. Pembelajaran di SD-A masih dilaksanakan dengan proses pembelajaran jarak jauh. Hal ini terkait kondisi daerah di SD-A ditetapkan sebagai zona merah covid. Siswa SD-A memiliki siswa muslim sebanyak 345 siswa sedangkan siswa non muslim ada 11 siswa. Ritual keagamaan pada agama islam sebelum pendemi adalah membaca asmaul husna sebelum memulai pembelajaran di pagi hari. Pembelajaran pada jam kedua dan selanjutnya adalah mengucapkan doa sebelum belajar secara nyaring bersama-sama. Ritual sebelum belajar selama pembelajaran jarak jauh dilakukan melalui intruksi tugas. Tugas siswa dikirim melalui media sosial online whatsapp group atau google classroom. Pesan yang disampaikan adalah "berdoalah sebelum mengerjakan tugas". Guru PAI tidak memantau secara individu. Guru PAI memantau secara kelompok di whatsapp group. Sekolah tidak menetapkan doa apa yang harus dibaca oleh siswa sebelum mengerjakan tugas. Berbeda halnya dengan pembelajaran luring, dimana sekolah memiliki peraturan untuk memulai pembelajaran di pagi hari dengan membaca asmaul husna. Kegiatan keagamaan lain yang biasa dilakukan di sekolah misalnya sholat dhuha berjamaah tidak diintruksikan oleh semua guru. Guru PAI saja yang mengintruksikan siswanya untuk melakukan sholat dhuha tetapi tidak setiap saat.
SD-B: Wawancara dilakukan pada wali kelas siswa SD-B. SD-B sejak awal bulan November melakukan pembelajaran di sekolah. Siswa secara bergilir ke sekolah seminggu sekali. Setiap sesi pertemuan ada tujuah siswa. Waktu pembelajaran di sekolah lebih singkat daripada waktu pembelajaran sebelum pandemi. Pada kegiatan di sekolah, doa sebelum belajar diucapkan bersama sama sebelum pembelajaran dimulai. Guru tidak memberikan intruksi khusus ritual agama apa yang dibaca sebelum belajar di rumah. Tidak semua tugas baik melalui whatsaap group maupun google classroom ada himbauan berdoa terlebih dahulu sebelum mulai mengerjakan.

Guru kelas memberikan tugas berupa buku kegiatan yang wajib diisi oleh orangtua (untuk siswa SD kelas 1). Kegiatan tersebut seperti kegiatan ibadah, kegiatan belajar anak di rumah dan kegiatan mengaji. Guru PAI mengontrol kegiatan anak melalui buku harian yang diisi oleh orangtua. Tidak ada ritual ibadah khusus sebelum belajar yang diintruksikan oleh sekolah. Orangtua yang diwawancarai tidak rutin melakukan doa terlebih dahulu sebelum belajar.

SD-C: Sekolah ini merupakan sekolah islam yang terkenal dengan program tahfidz. Nama lain SD ini adalah SD dengan program plus. SD ini belum melakukan pembelajaran secara offline. Pembelajaran masih dilakukan secara online atau jarak jauh. Orangtua mengambil tugas seminggu sekali ke sekolah. Tugas diberikan dalam bentuk hardfile yang berisi tugas-tugas siswa selama satu minggu. Di dalam tugas tersebut ada intruksi untuk berdoa sebelum mengerjakan tugas.Namun tidak ada peraturan khusus isi doa yang harud dipanjatkan. Orangtua juga tidak selalu memulai tugas dengan berdoa. Ritual keagamaan yang lain seperti menghafal AlQuran, dipantau oleh guru Pendidikan Agama Islam. Setiap minggu siswa wajib menyetorkan hafalan melalui video call dengan guru. Guru kelas memantau 
perkembangan siswa melalui video call. Pada video call tersebut guru langsung melihat perkembangan akademik siswa. Tidak ada intruksi berdoa atau melakukan ritual keagamaan tertentu.

SD-D: SD-D ini sudah melakukan pembelajaran di sekolah sejak pertengahan bulan November. Pembelajaran digilir dengan jumlah siswa yang terbatas yaitu antara enam sampai tujuh siswa setiap hari. Sebelum pembelajaran di kelas, sekolah memiliki program home visit. Program home visit dilakukan oleh guru pada kelompok belajar siswa. Namun pelakasanaannya di rumah salah satu anggota kelompok. Pada program home visit, guru memantau perkembangan siswa secara langsung. Guru juga memulai pembelajaran dengan doa sebelum belajar. Sebelum belajar siswa melaksanakan ritual belajar mengaji. Selama pembelajaran offline, guru pendidikan agama islam mendampingi siswa untuk mengaji iqra'. Siswa yang tidak terjadwal pembelajaran offline, tetap mendapatkan materi secara online melalui whatsapp group. Pembelajaran offline maupun online dimulai pada pukul 07.30 WIB. Antara jam 07.00 - 07.30 guru menghimbau pada orangtua untuk mendampingi anak memulai pembelajaran dengan menghafal surat pendek dan berdoa. Materi dan tugas diberikan pada pukul 07.30 WIB. Tidak ada aturan khusus mengenai bagaimana isi doa sebelum belajar pada kelas online. Namun pada kegiatan offline, anak memulai pembelajaran dengan membaca doa sebelum belajar.

Secara garis besar, ritual keagamaan sebelum pembelajaran selama masa pandemi dideskripsikan pada tabel di bawah ini:

Tabel 1

Ringkasan Ritual Keagamaan Sebelum Belajar

Selama Masa Pandemi

\begin{tabular}{|c|c|c|c|}
\hline $\begin{array}{l}\mathrm{N} \\
\mathrm{O}\end{array}$ & $\begin{array}{l}\text { Sekola } \\
\text { h }\end{array}$ & $\begin{array}{c}\text { Pembelajara } \\
\text { n selama } \\
\text { masa } \\
\text { pandemi } \\
\text { (Maret - } \\
\text { November } \\
\text { 2020) }\end{array}$ & $\begin{array}{c}\text { Kegiatan } \\
\text { Ritual } \\
\text { Keagamaan } \\
\text { sebelum } \\
\text { pembelajara } \\
\text { n }\end{array}$ \\
\hline 1 & SD A & $\begin{array}{l}\text { Pembelajara } \\
\text { n jarak jauh }\end{array}$ & $\begin{array}{l}\text { Ada intruksi } \\
\text { "berdoalah } \\
\text { sebelum } \\
\text { mengerjaka } \\
\text { n tugas" } \\
\text { pada setiap } \\
\text { tugas yang } \\
\text { diberikan } \\
\text { melalui } \\
\text { WAG dan } \\
\text { Google } \\
\text { classroom }\end{array}$ \\
\hline \multirow[t]{2}{*}{2} & \multirow[t]{2}{*}{ SD B } & $\begin{array}{l}\text { Maret - } \\
\text { September } \\
2020 \\
\text { pembelajara } \\
\text { n jarak jauh }\end{array}$ & $\begin{array}{l}\text { Ada intruksi } \\
\text { "berdoalah } \\
\text { sebelum } \\
\text { mengerjaka } \\
\text { n tugas" } \\
\text { pada setiap } \\
\text { tugas yang } \\
\text { diberikan } \\
\text { melalui } \\
\text { modul yang } \\
\text { diberikan di } \\
\text { setiap awal } \\
\text { minggu }\end{array}$ \\
\hline & & $\begin{array}{l}\text { November } \\
\text { mulai } \\
\text { pembelajara } \\
\text { n di } \\
\text { sekolah. } \\
\text { Siswa } \\
\text { bergantian } \\
\text { mengikuti } \\
\text { kegiatan di } \\
\text { sekolah. }\end{array}$ & $\begin{array}{l}\text { Berdoa } \\
\text { sebelum } \\
\text { belajar di } \\
\text { kelas }\end{array}$ \\
\hline
\end{tabular}




\begin{tabular}{|c|c|c|c|}
\hline 3 & SD C & $\begin{array}{l}\text { Pembelajara } \\
\mathrm{n} \text { jarak jauh }\end{array}$ & $\begin{array}{l}\text { Ada intruksi } \\
\text { "berdoalah } \\
\text { sebelum } \\
\text { mengerjaka } \\
\text { n tugas" } \\
\text { pada setiap } \\
\text { tugas yang } \\
\text { diberikan } \\
\text { melalui } \\
\text { modul yang } \\
\text { diberikan di } \\
\text { setiap awal } \\
\text { minggu }\end{array}$ \\
\hline \multirow[t]{3}{*}{4} & \multirow[t]{3}{*}{ SD D } & $\begin{array}{l}\text { Maret - } \\
\text { April 2020, } \\
\text { pembelajara } \\
\text { n jarak jauh }\end{array}$ & $\begin{array}{l}\text { Intruksi } \\
\text { untuk } \\
\text { melakukan } \\
\text { ritual } \\
\text { keagamaan } \\
\text { seperti } \\
\text { berdoa, } \\
\text { membaca } \\
\text { Al-Quran } \\
\text { dan } \\
\text { menghafal } \\
\text { surat-surat } \\
\text { pendek }\end{array}$ \\
\hline & & $\begin{array}{l}\text { April - } \\
\text { September } \\
2020, \\
\text { pelaksanaan } \\
\text { program } \\
\text { home visit } \\
\text { per- } \\
\text { kelompok }\end{array}$ & $\begin{array}{l}\text { Siswa yang } \\
\text { terjadwal } \\
\text { home visit, } \\
\text { melakukan } \\
\text { berdoa } \\
\text { sebelum } \\
\text { belajar dan } \\
\text { menghafal } \\
\text { surat } \\
\text { pendek } \\
\text { bersama- } \\
\text { sama }\end{array}$ \\
\hline & & $\begin{array}{l}\text { November } \\
2020 \text { mulai } \\
\text { pembelajara }\end{array}$ & $\begin{array}{l}\text { Siswa yang } \\
\text { terjadwal } \\
\text { home visit, }\end{array}$ \\
\hline
\end{tabular}

\begin{tabular}{|l|l|l|l|}
\hline & n di & melakukan \\
& sekolah. & berdoa \\
& Siswa & sebelum \\
bergantian & belajar dan \\
& mengikuti & menghafal \\
& kegiatan di & surat \\
& sekolah. & pendek \\
& & $\begin{array}{l}\text { bersama- } \\
\text { sama }\end{array}$ \\
\hline
\end{tabular}

satu aspek dari religiusitas (Jalaludin, 2007). Ritual keagamaan merupakan salah satu stimulasi perkembangan agama untuk anak (Setiani, et al., 2020). Harapannya melalui ritual ini akan terbentuk pribadi yang beragama. Ritual keagamaan sebelum pembelajaran pada pembelajaran tatap muka sangat beraneka ragam bentuknya mulai dari membaca asmaul husna, sholat dhuha berjamaah, mengaji dan membaca doa sebelum belajar secara bersama sama.

Pada bulan tanggal 16 Maret 2020, pemerintah mulai membuat kebijakan baru di sebagian besar sekolah di Indonesia. Ke-empat sekolah tempat penelitian juga terdampak covid. Banyak sekali penyesuaian yang telah dilakukan salah satunya kegiatan membaca doa. Empat sekolah memiliki dinamika yang berbedabeda.

Sekolah A sampai sejak bulan Maret sampai November 2020 belum pernah melakukan kegiatan secara offline. Ritual keagamaan sebelum belajar diintruksikan bersama tugas yang diberikan kepada orangtua. Guru menghimbau pada siswa untuk berdoa sebelum belajar dan mengerjakan tugas. Orangtua merupakan salah satu faktor pembentuk religiusitas (Subandi, 2019). Guru tidak bisa mengontrol pada semua siswanya apakah perilaku berdoa ini dilakukan selama pembelajaran di rumah. 
Sekolah B memiliki karakteristik yang hampir sama dengan sekolah A yaitu sekolah Negeri yang memiliki siswa dengan keberagamaan agama. Namun sekolah B sudah ada kegiatan belajar di sekolah yang dilakukan dengan cara bergilir. Doa dipanjatkan bersama-sama dengan membaca basmallah. Sekolah tidak memiliki aturan doa apa yang harus dipanjatkan oleh siswanya sebelum belajar. Orangtua yang diwawancarai juga jarang melakukan berdoa sebelum belajar. Perilaku orangtua sangat mempengaruhi perilaku keberagamaan anak (Diesendruck, 2008). Religious instinck anak bisa dikembangkan melalui pembiasaan berdoa sebelum belajar, apabila hal ini tidak ditanamkan maka anak akan belajar tanpa memahami bahwa ilmu yang dipelajari merupakan ilmu dari TuhanNya.

Sekolah C dan D merupakan sekolah swasta berbasis islam. Kedua sekolah ini memiliki kegiatan keagamaan yang lebih banyak dibandingkan dengan dua sekolah yang lain. Sekolah berbasis agama merupakan salah satu faktor yang mempengaruhi religiusitas anak (Khalek, 2009). Ritual keagamaan pada kedua sekolah ini diintruksikan bersama tugas yang diberikan. Sekolah C memberikan tugas melalui modul yang diberikan seminggu sekali pada wali murid. Di dalam modul tersebut orangtua dihimbau untuk melaksanakan perilaku berdoa sebelum belajar. Berbeda halnya dengan sekolah D. Sekolah D lebih banyak jenis ritual keagamaan sebelum belajar. Ritual keagamaan yang diintruksikan 30 menit sebelum belajar melalui Whatsapp Group meliputi berdoa, menghafal surat pendek dan membaca AlQuran. Namun guru tidak bisa memantau pada semua siswa apakah sudah dilakukan di rumah atau belum. Sekolah D memiliki program home visit dan kegiatan pembelajaran offline. Guru dapat memantau ritual keagamaaan siswa yang terjadwal pada pembelajaran tatap muka di kelas.

Semua siswa pada penelitian ini adalah siswa yang masih tergolong anak anak. Proses imitasi sangat penting dalam membentuk perilaku ritual keagamaan maupun keyakinan anak (Diesendruck, 2008). Imitasi diakukan secara langsung ketika anak melihat orangtua melakukan kegiatan keagamaan.

\section{E. SIMPULAN}

Ada beberapa hal yang bisa disimpulkan dari penelitian ini yaitu kegiatan ritual keagamaan sebelum pembelaajran pada empat sekolah selama masa pandemi berbeda-beda. Sekolah yang masih melakukan pembelajaran jarak jauh meliputi intruksi berdoa melalui tugas yang diberikan baik melalui media online maupun modul yang diambil oleh orangtua di awal minggu. Pada beberapa sekolah yang sudah melakukan pembelajaran tatap muka bisa melakukan ritual keagamaan sebelum berdoa secara bersama-sama. Pada pembelajaran tatap muka, guru bisa memandu dan memantau kegiatan berdoa. Selama pembelajaran online, orangtua yang menjadi fasilitator. 


\section{DAFTAR PUSTAKA}

Amri, S., Ismawati, T., \& Armila, A. (2020). Studi Analisis Nilai Nilai Pendidikan Karakter Perspektif Syech Muhammad Khudhari Bek dalam Kitab Khulashah Nurul Yakin. Attractive: Innovative Education Journal, 2(2), 77-88.

Bahri, M. S., Mispani, M., \& Tukiran, T. (2021). Education Character Perspective of $\mathrm{KH}$ Hasyim and Hafidz Hasan Al-Mas' udi. Bulletin of Pedagogical Research, 1(1), 1645.

Cahyono, H., Suhono, S., \& Khumairo, A. (2018). Pendidikan Karakter Bagi Pelaku Pedofilia (sebuah Strategi dalam Mengatasi Amoral). JMKSP (Jurnal Manajemen, Kepemimpinan, dan Supervisi Pendidikan), 3(1), 1-19.

Desmon, S. M. (2010). Religious Development: How (and Why) Does Religiousity Change From Adolescence to Young Adulthood. Sociological Perspective, 52(2), 247 - 270.

Diesendruck, G. \&. (2008, Januari). God's Categories: The Effect of The Religiosity on Children Teleological and Essensialist Beliefs ABout Categories. Cognition, 110(1), 100 - 114.

Fathoni, M., Fadillah, K., Jannah, S. R., \& Yusuf, M. (2021). The Efforts of Teachers' Islamic Education in Forming Students' Religious Character at SMPN 5 Gunung Labuhna Way Kanan. Bulletin of Pedagogical Research, 1(1), 106123

Fitriansyah, A. (2018). Pengaruh Kebiasaan Membaca Al-Quran Terhadap Kecerdasan Spiritual di SMP 2 Kota Blitar. IAIN Tulungagung, Jurusan Pendidikan Agama Islam, Fakultas Tarbiyah dan Ilmu Kegiruan. Tulungagung: IAIN Tulungagung.
Gufron, M., \& Risnawati, S. (2010). TeoriTeori Psikologi. Yogyakarta: ArRuzz Media Group.

Ilyasa, F., Rahmayanti, H., Muzani, M., Ichsan, I. Z., \& Suhono, S. (2020). Environmental education for prevent disaster: a survey of students knowledge in beginning new normal of COVID-19. International Journal on Advanced Science, Education, and Religion, $3(2), 1-8$.

Jalaludin. (2007). Psikologi Agama. Jakarta: Raja Grafindo.

Julianto, V., \& Estem, M. (2011, Juni 2011). The Effect of Reciting Holy Quran toward Short Term Memory Ability Analysed Trought the Changing Brain Wave. Jurnal Psikologi, 38, 17-29.

Khalek, A. (2009). Religiousity, Subjective Well-Being and Depression in Saudi Children and Adolescent. Mental Healt, Religion and Culture, 803-815.

Komara, I. B. (2016). Hubungan antara Kepercayaan Diri dengan Prestasi Belajar dan Perencanaan Karir Siswa. Psikopedagogia, 5, 33-42.

Kusuma, F. (2011). Asma'ul Husna Bentuk Padanan, Pengertian dan Deskrisi: Dalam Ar.Risalah, Quantum Asma'ul Husna dan Menyingkap Tabir Ilahi Asma'ul Husna dalam Prespektif Al-Quran. Surakarta: Fakultas Keguruan dan Ilmu Pendidikan Universitas Muhammadiyah Surakarta.

Kusumawardhani, M. (2013). Implementasi Nilai-Nilai

Pendidikan Karakter Di Sekolah Menengah Kejuruan (SMK) Negeri 4 Yogyakarta. Yogyakarta: Program Studi Teknik Boga, Fakultas Teknik, Universitas Negeri Yogyakarta.

Moleong, L. J. (2014). Metodologi Penelitian Kualitatif. Bandung : Rosdakarya. 
Mursalim. (2011, Juni 1). Doa Dalam Perspektif AlQuran. Jurnal Al Ulum, 11, 63-78.

Nayef, E., \& Wahab, M. (2018). The Effect of Recitation Quran on the Human Emotion. International Journal of Academic Research in Business \& Social Sciences, 50-70.

Nayef, E., \& Wahab, M. (2018). The Effect of the Quran Recitation on Mental Health of The Iranian Medical Staff. Journal of Nursing Education and Practice, 30-36.

Palufi, A. N., \& Syahid, A. (2020). Metode Yanbu'a Sebagai Pedoman Membaca Al-Qur'an. Attractive: Innovative Education Journal, 2(1), 32-40

Rachmadhani, F. (2019, December 06). Tafsir Surat Al-Alaq. (A. Aisah, Interviewer)

Ramlah, Firmansyah, D., \& Zubair , H. (2014). Pengaruh Gaya Belajar dan Keaktifan Siswa Terhadap Prestasi Matematika Pada Siswa SMP Karawang. Jurnal Ilmiah Solusi, 68-75.

Rahimah, R., Juriah, N., Karimah, N., Hilmatunnisa, H., \& Sandra, T. (2020). The Problems and Solutions for Learning Activities during Covid-19 Pandemic Disruption in Hidayatul Insan Pondok School. Bulletin of Community Engagement, 1(1), 1320.

Santrock, J. W. (2017). Psikologi Pendidikan. Jakarta: Putra Grafika.

Setiani, A. I., Laili, N., \& Abimanto, D. (2020). Strategi Pengembangan Keberagamaan Mahasiswa Di Universitas Islam Negeri Sunan Gunung Djati Bandung Melalui Praktik Tilawah. Attractive: Innovative Education Journal, 2(1), 26-31

Siswoyo, A. (2018, February 20). Motivasi Belajar. Retrieved December 4, 2019, from Motivasi Belajar: gussiswoyo.com/motivasibelajar/menanamkan-kebiasaan- membaca-asmaul-husna-padamurid-sebelum-belajar-di-sekolah/ Slameto. (2010). Belajar dan FaktorFaktor yang Mempengaruhinya. Jakarta: Rineka Cipta.

Subandi, M. A. (2019). Psikologi Agama \& Kesehatan Mental. Yogyakarta: Pustaka Pelajar.

Sugiyono. (2011). Metode Penelitian Kuantitatif, Kualitatif dan $R \& D$. Bandung: Alfabeta.

Syah, M. (2010). Psikologi Pendidikan. Bandung: Remaja Rosdakarya.

Syaikhoni, Y., Subandi, S., Fadillah, K., \& Pratiwi, W. (2021). The Implementation of Student Discipline Character through School and Parents' Collaboration. Bulletin of Pedagogical Research, 1(1), 174-186.

Tratner, A., Sela, Y., Lopes, G., \& Erkhe, A. (2017). Development and Initial Psychometric Assesment Chilhood Religious Experience Inventory Primary Caregiver. Personality and Individual Differences, 1-9.

Wahab, M. (2011). Simbol-Simbol Agama. Jurnal Substansia, 79-84.

Yolanda, A. T., \& Kailola, L. G. (2021). The Effect of Teacher Competence and Emotional Intelligence on Students Development Character at Senior High School Kristen Barana'. Bulletin of Science Education, 1(2), 164-181

Yin, R. K. (2014). Studi Kasus: Desain \& Metode. Jakarta: Rajawali Press. 